\title{
Internet's Role in the Integration of Supply Chains of Manufacturing Organizations in Brazil
}

\author{
Alexandre Reis Graeml \\ Universidade Positivo (UP) / Universidade Tecnologica Federal do Parana (UTFPR) \\ graeml@fulbrightweb.org \\ Zandra Balbinot \\ Universidade Federal do Paraná (UFPR) \\ zbalbinot@hotmail.com \\ João Mário Csillag \\ Escola de Administração de Empresas da Fundação Getúlio Vargas (FGV-SP) \\ joao.mario.csillag@fgv.br
}

\begin{abstract}
This paper presents the results of a study about the impact of the Internet and other information technologies on supply chain management, as perceived by managers in the field. Two almost identical surveys were applied to 105 Brazilian manufacturing companies, three years apart from one another, aiming to depict changes on managers' perceptions over time. Answers to the questions were organized and presented in bar graphs segmented based on the year and the companies' size. Several analyses were then possible, which helped to understand how the scenario evolved over time and to depict trends for the future.Answers to the questions were organized and presented in bar graphs segmented by year and company size. Several analyses were possible, which enlightened us as to how the scenario evolved from 2003/2004 to 2006/2007 and provided data with which to project trends for the future.
\end{abstract}

KEYWORDS: Internet, information technology, supply chain management, integration, manufacturing.

\section{INTRODUCTION}

Physical products, such as cars and computers, are clearly different from information products, such as magazines and music, with respect to the production and logistics tasks involved in making them available to customers. Physical services, such as transportation, also differ from information services, such as news providers, in that matter. These differences are essential to understanding the kind of benefit that the Internet can provide to organizations that produce or commercialize them.

Information products and services are those that can be digitized, i.e., converted into bits and bytes. Typically, they involve very low production marginal costs since, after the first unit is produced, their reproduction does not require significant effort (Shapiro \& Varian, 1998). With the possibility of delivering such products and services through the Web, distribution costs have almost disappeared, as they can be elec- tronically transferred from the premises of the vendor to a place of convenience for the customer.

According to Starr (2003), companies such as eBay (electronic auctions), Orbitz and Priceline.com (air tickets, hotels and car rental), to name but a few well known Internet operations, do not concern themselves about managing inventory nor about developing complex logistics infrastructures to deliver their products. In fact, for information products and services, warehousing and shipping are no longer important issues: information does not require a physical media to convey it any longer.

Information products and services can be reproduced and moved almost instantaneously and with very little limitation (Geoffrion \& Krishnan, 2001). Vendors can use the Web to develop their products and services. They can then advertise their products to potential buyers; take orders; replicate and deliver them to customers; receive payment; get feedback from 
consumers and provide after-sales support - all electronically. Impressed with such possibilities of virtual companies, The Economist once wrote the following about eBay: "The Internet auctioneer is not a B2C company but a near-perfect model of software and network economics. Once its programmers built the auction tools, eBay could almost run itself." (2000, p. 67). The physical supply chain for information products and services is probably going to become, with time, less relevant, as physical processes and logistics are gradually being replaced by virtual equivalents, based on the Internet, with cost advantages as well as added flexibility and delivery diligence.

Companies that have their operations based on pure physical products and services, on the other hand, can only use the Internet to support part of their activities. The delivery of physical goods or services cannot be performed through the Web. Physical distribution is still required from some point along the supply chain, whether it is where products are manufactured or stored or at the place where customer wants them delivered. Geoffrion and Krishnan (2001) remark that "physical products and services do not enjoy the magical qualities" that make information products and services such a good fit to the Internet.

Nonetheless, a company's Web site may represent a good shopping window for displaying the company's physical products or services and it can also be used to carry out the transaction, collect payment, establish a communications channel with customers and as the means to develop after-sales activities. Such organizations may also find that the Internet is a useful means of coordinating activities and integrating processes with suppliers and customers, with the intent of delivering a higher quality product in a faster manner.

The research project that originated the data analyzed in this paper was developed with the purpose of providing a better understanding of the way manufacturing companies, which usually produce just such physical products, use the Internet to support their strategies and business practices. Although the project had a larger scope, this paper has the objective of evaluating the responses provided by the participants relating to their current use of the Internet (or their intention to use it in the near future) to coordinate and integrate the supply chain - one of the greatest challenges in marketing physical goods in a world that is increasingly more virtual.
The next section presents the reasons found in the literature for organizations to use the Internet and other IT to coordinate their activities with other companies in the supply chain. Following that, the methodological procedures used to collect and analyze the data are described. Then, the findings are shown and some conclusions and final considerations presented.

\section{LITERATURE REVIEW}

The possibility of using the internet to coordinate activities with business partners

The struggle to improve coordination with suppliers, thereby increasing the efficiency of the supply chain as a whole, has demanded that companies and the suppliers of logistics services carry out massive investments in technology. The ideal situation for these actors would be (or will be) to be able to tap into information about sales to consumers in real time in order to define subsequent production activity (Ferdows, 2006; Cottrill, 2003). To do this demands the following:

- agility in the information flow from the consumer towards the producer and

- production and logistics flexibility from the producer towards the consumer.

With these capacities in place, the organization is able to get closer to the SOMO (sell one, make one) performance target standard, i.e. only produce a new item after another one has been sold. This is imperative now that customers set the rhythm of consumption and determine the specifications of what they want to buy.

The Internet may become an important platform for the exchange of data among business partners, contributing to the reduction of lead-times and, therefore, attenuating the nasty consequences of poor information flow along the supply chain, particularly the Forrester effect, also known as the "bull whip effect", which is the amplification of demand variation for a specific product over the supply chain, when there is fluctuation farther down it ( $\mathrm{O}^{\prime}$ Donnell et al., 2006; Saab \& Corrêa, 2004).

Below, we present a few technologies that benefit from the infrastructure provided by the Internet, which can be used in order to improve the information flow, as well as a few practices and techniques that help to coordinate activities along the supply chain. 


\section{Electronic data interchange (EDI)}

One very important technology used by organizations to ensure quick information flow with suppliers is the so called electronic data interchange (EDI) or its variations for the Internet (Schaffer, 1998).

EDI has been in the market for over 20 years as a standardized way of transmitting business forms and documents among suppliers and customers, such as purchase orders, invoices, shipment notices and delivery schedules (Sweet, 1999; Bednarz, 2004). Such technology is responsible for $80 \%$ to $90 \%$ of the information flow among companies, according to Sliwa (2004), who does not believe it is going to be replaced, in the short run, by any other means of trading information.

There are many reasons for the use of EDI for the transmission of transactional data among business partners, some of which are worthy of mention here (Coyle, Bardi \& Novack, 1999; Sweet, 1999; Reid \& Sanders, 2004; Saab \& Corrêa, 2004):

- the possibility of quick access to the information in a standardized way;

- the elimination of human transcription and interpretation errors;

- the reduction of transaction costs, as a result of the elimination of most labor costs related to the manual filling in of forms;

- improvement of inventory control;

- the reduction of telephone and fax costs;

- improvement of service to the customer;

- quick warnings about problems with shipments, reducing the negative impact of the situation;

- the possibility of auditing transactions; and

- the reduction of purchase batch size (as a result of the reduction of transaction costs).

If those reasons are not enough, many times the customer still demands EDI be used for the transmission of operational and billing information, giving the supplier no choice other than to embrace the system.

Due to its high implementation and maintenance costs, however, traditional EDI has been confined to large companies and their major suppliers, among whom there was enough information sharing taking place to justify it. The traditional EDI technology demanded its users hire the services of a VAN (value added network) and cope with the costs that such a service entails. In addition to that, a sophisticated IT infra-structure was required, involving complex proprietary software (Bednarz, 2004). Most EDI applications focused on the manufacturing industry whose processes, particularly those involving supply chain partners, demand a lot of information sharing (Albertin, 2003).

Marques and Di Serio (2000) say that the Internet has provided a public infra-structure through which transactions can be performed, allowing for the electronic integration of companies of all sizes. In effect, the more recent possibility of carrying out EDI transactions over the Web is democratizing its use, as it only requires a Web browser and the installation of basic software. This new possibility significantly reduced the cost per transaction of adopting EDI (Sliwa, 2004). Thus, EDI technology is starting to spread to the service industry and smaller industrial manufacturers as well. According to Bednarz (2004), EDI transactions over the Web are growing at 50 to $60 \%$ a year, while traditional EDI, based on VANs, has stagnated. That means that companies that implemented traditional EDI systems in the past continue to use and benefit from the technology, simply because it works. Newcomers, however, adopt Internet solutions, instead, because they are cheaper and more flexible (Sweet, 1999).

Instead of using VANs to send data related to a transaction, as happens for traditional EDI, XML-based systems are able to convey business documents in a much cheaper way, using Internet's usual protocols, such as HTTP (HyperText Transfer Protocol), SSL (Secure Sockets Layer) or FTP (File Transfer Protocol). That is why Sweet (1999) believes that companies that did not implement traditional EDI systems in the past will not find a good reason to do it in the future. Most likely, they will go straight to a B2B solution, which may involve the use of technologies such as XML or the AS2 (Applicability Statement 2) protocol, which has been promoted by WalMart to its suppliers (Sliwa, 2004). In fact, considering that WalMart is the largest retailer in the world, its choice of a technological solution works almost like an instant definition of an industry standard.

\section{Extranets}

Organizations began using the Internet to visualize content that was being openly made available 
by other companies and in order to publish information about themselves that they considered to be convenient and relevant for general access. But the Web was soon also being considered a good platform for the publication of content of restricted interest, as users became acquainted with its environment and available resources, reducing the cost and need of additional training. As a result, many organizations started to structure internal networks using tools and services that are similar to those of the Internet, only protecting them from external access. Such internal networks, used to make information available and to share it among the company's employees are called "intranets". After developing intranets, the next step was to allow business partners to have access to part of such network, or networks developed specifically for them, with the purpose of improving the communication and integration of supply chain links. That is how "extranets" came about. They are networks that use the Internet's infra-structure and services, thereby congregating the organization and its suppliers/ customers, in a protected way, while preventing the access of other parties (O'Brien, 2001).

\section{METHODOLOGY}

The research project that provided the data analyzed in this paper was developed to improve the understanding of how Brazilian manufacturing companies use the Internet to support their strategies and business practices. This paper, specifically, discusses possible uses of the Internet for coordination between suppliers and customers.

Manufacturing companies of São Paulo, the most industrialized state in Brazil, were surveyed on two different occasions:

- from November 2003 to February 2004

- from November 2006 to February 2007

The questionnaire was pre-tested in 2003 with respect to its content by a group of executives working in the field. They gave important contributions that allowed us to make questions more accessible and understandable to the actual participants, at a later stage. With respect to the format, the authors randomly separated one per cent of the whole database and sent the questionnaire to those companies a month in advance, for the 2003/2004 survey. No changes in format were required as a result of the pre-test. No pre-test was carried out for the
2006/2007 survey, because the questionnaire was almost identical to the one applied in 2003/2004.

The convenience sample used for this research project consisted of respondents that participated in both surveys (2003/2004 and 2006/2007). The fact that the sample was a convenience sample (only companies that agreed to participate were taken into account) means that it could not be considered a probabilistic distribution of the population. Although no simple and definite solution was found to ensure sample representativeness, measures were taken to improve the 2003/2004 survey's sample acceptability. One hundred companies whose e-mail addresses in the database proved invalid were contacted by telephone and asked to provide an alternative (working) e-mail address. In addition, one hundred companies that did not have any e-mail address in the database were contacted by telephone, with a request for an existing e-mail address. The great majority of them did provide a valid e-mail address.

The researchers were especially concerned with issues of similarity between the convenience sample and the population because the survey was about the manufacturing companies' use of the Internet and companies were being contacted electronically, which could be argued to be biasing. The two hundred additional phone calls to non-respondents (invalid e-mail and no e-mail in the database) helped refute that possibility and led the researchers to assume that surveyed companies did not represent a biased sample of the population.

For the 2003/2004 sample, comparisons were also carried out with respect to demographic data available in the database about the population. No evidence was detected of significant differences between sample and population. On the contrary, $\chi 2$ tests based on the location of companies (region within the state of São Paulo) and size were very favorable.

For the 2006/2007 sample (a sub-sample of the previous one), the only additional precaution was the $\chi 2$ test with respect to the size of surveyed companies. It was not possible to check similarity with the population with respect to location because location possibilities were many and the size of the sample was not large enough (105 respondents).

In 2003/2004, companies were contacted through an e-mail message that had an MS Word automated form attached to it. The questionnaire needed to be returned by the respondent after completion. 
655 answers were obtained, which represented ca. $8 \%$ of the companies with valid e-mail addresses in the database.

In 2006/2007, participants were also surveyed electronically. However, instead of the form being attached to an e-mail message, companies only received an electronic message indicating the survey's website and inviting them to participate. 105 companies provided valid answers, corresponding to $16 \%$ of the population, i.e., the convenience sample of the 2003/2004 survey.

The two surveys consisted of the same set of questions, which could be quickly answered by clicking the mouse on the suitable alternative from dropdown menus.

The next section presents the results that were achieved for the following questions included in the survey that the participants filled in Nov2003/ Fev2004 and again in Nov2006/ Fev2007:

Did the Internet change the level of integration of the company's supply chain, over the last 3 years?

Does the company use, or intend to start using, extranets and other information systems to relate to customers and suppliers and to improve the information flow along the supply chain?

The data from companies that only participated in the 2003/2004 survey was disregarded. The analysis focused on the answers given by the 105 companies that participated in the two surveys. That was necessary because the researchers wanted to depict the influence of time. Of course, collecting data at two different moments is not enough for a truly longitudinal study but it does help when detecting trends, which can be studied further in the future using more suitable methods.

Another reason for using the 105 companies that participated in the two surveys was that the respondent was exactly the same person in the two occasions for 88 of them. It was not possible to identify the respondent for 11 companies and only 6 companies definitely had their data reported by two different people. The fact that, for the most part, the same people filled in the questionnaire in 2003/2004 and in 2006/2007 improves the comparability of the two samples. One should keep in mind that surveys deal with perceptions, which may vary from one person to another, even if they belong to the same organiza- tion and are faced with the same situations.

\section{RESULTS}

Here, we present the results of the survey applied to manufacturers in the state of São Paulo, Brazil. The authors intended to assess the intensity of use of the Internet and other surveyed technologies/practices to find out how manufacturing organizations use them to better integrate their supply chains.

Companies that participated in the survey were separated according to their size. This segmentation was considered important because Internet adoption is highly influenced by this factor.

Then, graphs were generated showing the behavior of each of the variables studied, taking into account the company size and the timing (remember that participants answered the questionnaire twice: first in Nov2003/Feb2004 and again in Nov2006/ Feb2007). Graphs express the perception of the participants with respect to the intensity of their use of the Internet and other IT to improve integration of the supply chain. They also express the respondents' expectations for the next 3 years, at each of the two occasions when asked.

Figures 1 to 6 present stack-bars discriminated by the size of the company and time. Inside each rectangle that forms a vertical bar, the number of companies appears, in absolute terms, which provided a specific answer to the proposed question (according to the legend below each graph). The horizontal axis presents a percentage scale, used in order to provide a "relative" value for the absolute figures contained inside the rectangles.

Impact of the Internet and other IT on the integration of the supply chain

When asked about the impact of the Internet and other IT on the integration of the supply chain, over the last 3 years, respondents demonstrated that they consider that the impact was considerable. Analyzing Figure 1, one notes that ca. 36.2\% $((1+3+15+19) / 105)$ of the 2006 respondents said that change was, at least, reasonable. In 2003, 22.9\% ((10+14)/105) had that impression. One also notices that larger companies tend to consider that the impact of the Internet was larger than smaller ones, although companies of all sizes perceive more significant change now (2006 survey) than they did three years ago (2003 survey). 


\section{Figure 1}

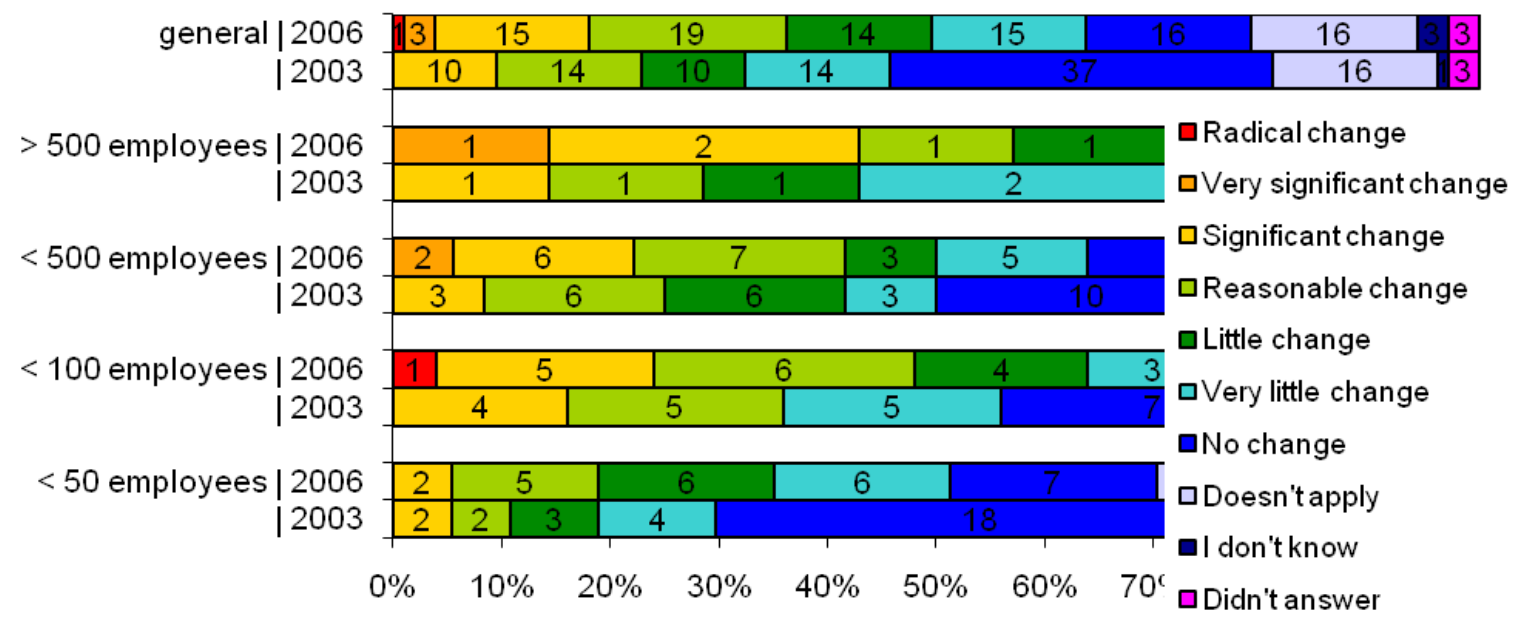

Impacts of the Internet and other IT on the integration of the supply chain, segmented according to company size and survey year

Information systems about the suppliers of the suppliers (upstream the supply chain)

In order to understand the importance given by the manufacturers to the integration of the supply chain, they were questioned about whether they had information systems that allowed them to gather information about the suppliers of their suppliers (not just about first tier suppliers), to improve decision making on production planning and inventory levels to keep.

The results are presented in Figure 2. Curiously, considering that for most other questions large companies revealed that they use the Internet more intensively than smaller ones, when the matter refers to information systems on the upstream side of the supply chain smaller companies show greater inter- est, although still very low. None of the large companies claimed to use information systems, at least to a moderate extent, to monitor their upstream supply chain. In general, i.e., without size segmentation, $56.2 \%((26+33) / 105)$ of companies do not intend to gather that kind of information or consider it doesn't apply to their businesses (2006 survey). This figure increased from the $46.7 \%((27+22) / 105)$ obtained from the same sample in 2003. This is also noteworthy because one would think that the use of the Internet and other IS for that purpose could only increase. It could mean that, in spite of all the fuss about supply chain management, this kind of approach is more present in academic studies than in business practice. Of course, this could also be the result of a small sample, particularly in the case of large companies, which, as it was said before, tend to lead the way in the introduction of new technologies. Analyzing the graph on Figure 2, one realizes that this does not seem to be the case for this issue.

\section{Figure 2}

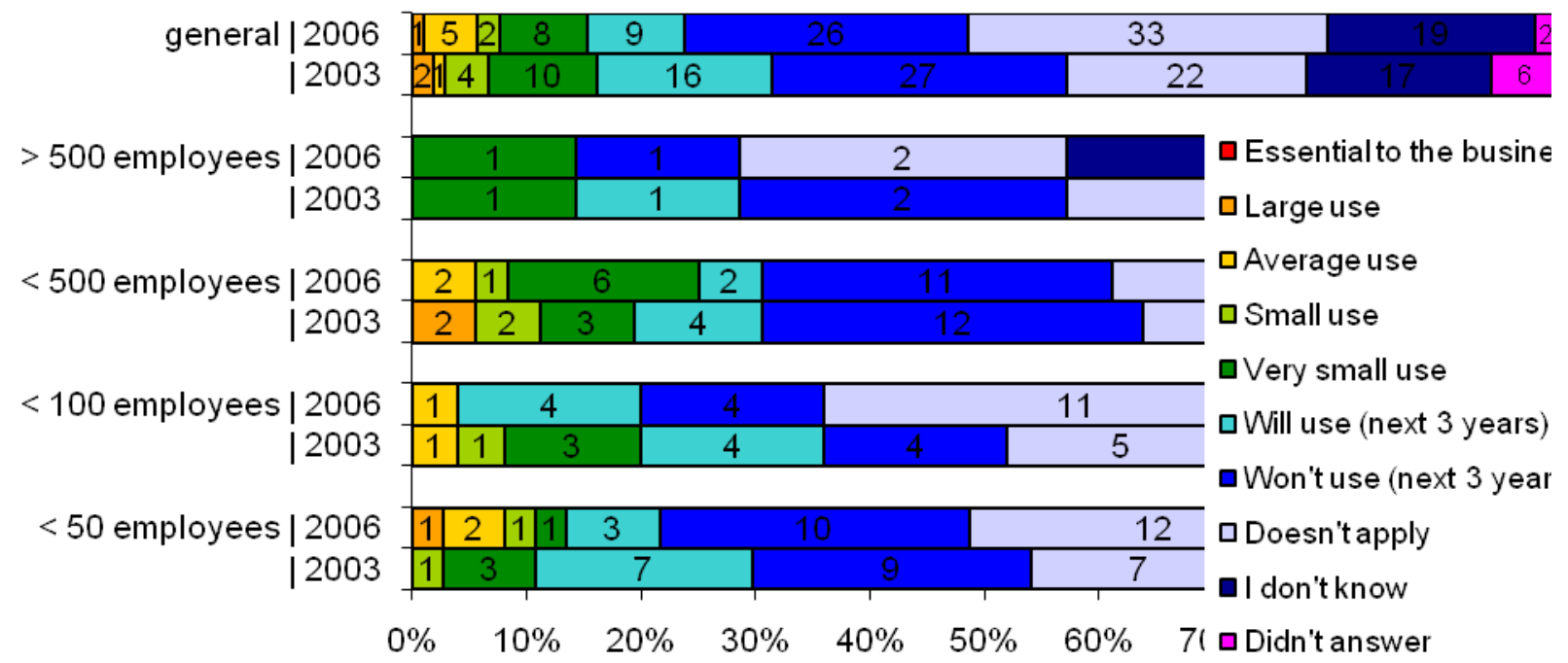


Current use of information systems about the suppliers of the suppliers (upstream side of the supply chain), segmented according to company size and survey year

Information systems about the customers of the customers (downstream links of the supply chain)

The same way participants were questioned about the collection of data on the upstream links of the supply chain, the survey also concerned itself with the information companies gathered on downstream links in their supply chains, including the actual consumers of their products. The results did not depict any increase trend regarding use of the Internet for that purpose. On the contrary, Figure 3 shows that the number of companies that claim that they will not use the Web to obtain this kind of information or that it is not applicable to their businesses increased for companies of all sizes: they made up $44.8 \%$ of respondents in $2003((23+24) / 105)$, and now they make up $61.0 \%((28+36) / 105)$. As most of the respondents were exactly the same people in the two occasions (2003 and 2006), is this observed regression in their perceptions is somewhat surprising. Just as an example, 3 of the 7 large companies in the sample had previously (2003) stated that the Internet and other IT were used, at least to a moderate extent, to gather information from downstream links of their supply chains. In 2006, only one of them claimed that the company used the Internet for that purpose, at a much lower level ("small use"). Although surprising, such results are not incompatible, as surveys capture people's perceptions, which are a proxy to the actual situation but not the same thing as it.

Figure 3

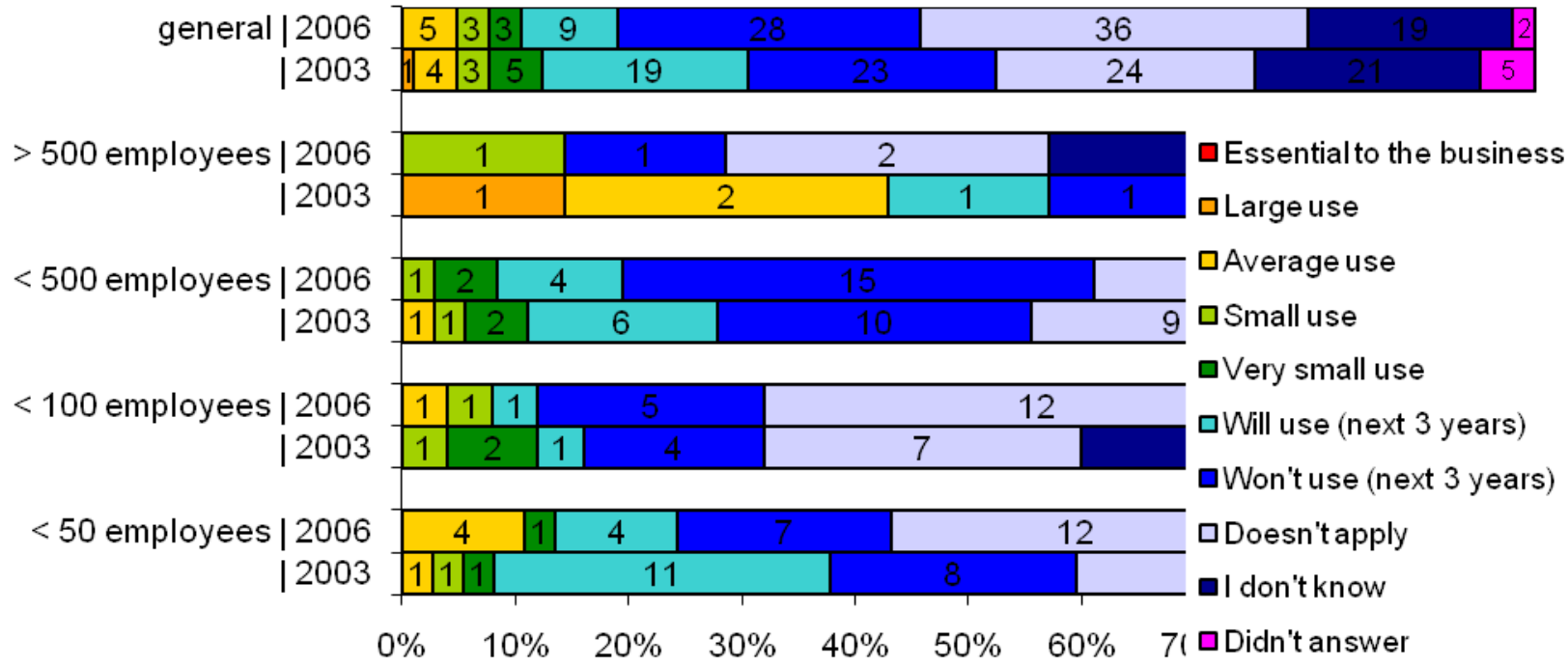

Current use of information systems about the customers of the customers (downstream side of the value chain), segmented according to company size and survey year

\section{Electronic data interchange among business part- ners (EDI)}

EDI presented a relatively high level of usage, when compared to other tools that were surveyed. Among large companies, 4 out of 7 respondents claimed that they used EDI at least to a moderate extent in 2006 (in 2003, only 2 companies had the same perception). Usage is lower for smaller companies, although many claim that they will start using this technology within the next 3 years (see Figure 4).
No distinction was made, in the 2003 survey, between traditional EDI (using VANs) and Web EDI, using XML, AS2 or some other information exchange standard. In the 2006 survey, such discrimination was made. The results confirmed the literature, showing that Web EDI is growing, while traditional EDI is not gaining new adopters: $11.4 \%$ of the participants said that they use traditional EDI, while $16.2 \%$ use Web EDI. Only 5.7\% claim that they will start using traditional EDI over the next 3 years, while $18.1 \%$ of them plan to start using Web EDI. The preference for Web EDI is also noteworthy when one analyzes rejection rates: $50.5 \%$ of the respondents say that they will not implement traditional EDI over the next 3 years or that it does not apply to their businesses. That only happens to $37.1 \%$ of the respondents, with respect to 
Web EDI. 10.5\% of the companies do not use any form of EDI but plan to implement Web EDI soon, though they are not planning to invest on traditional EDI.

Figure 4

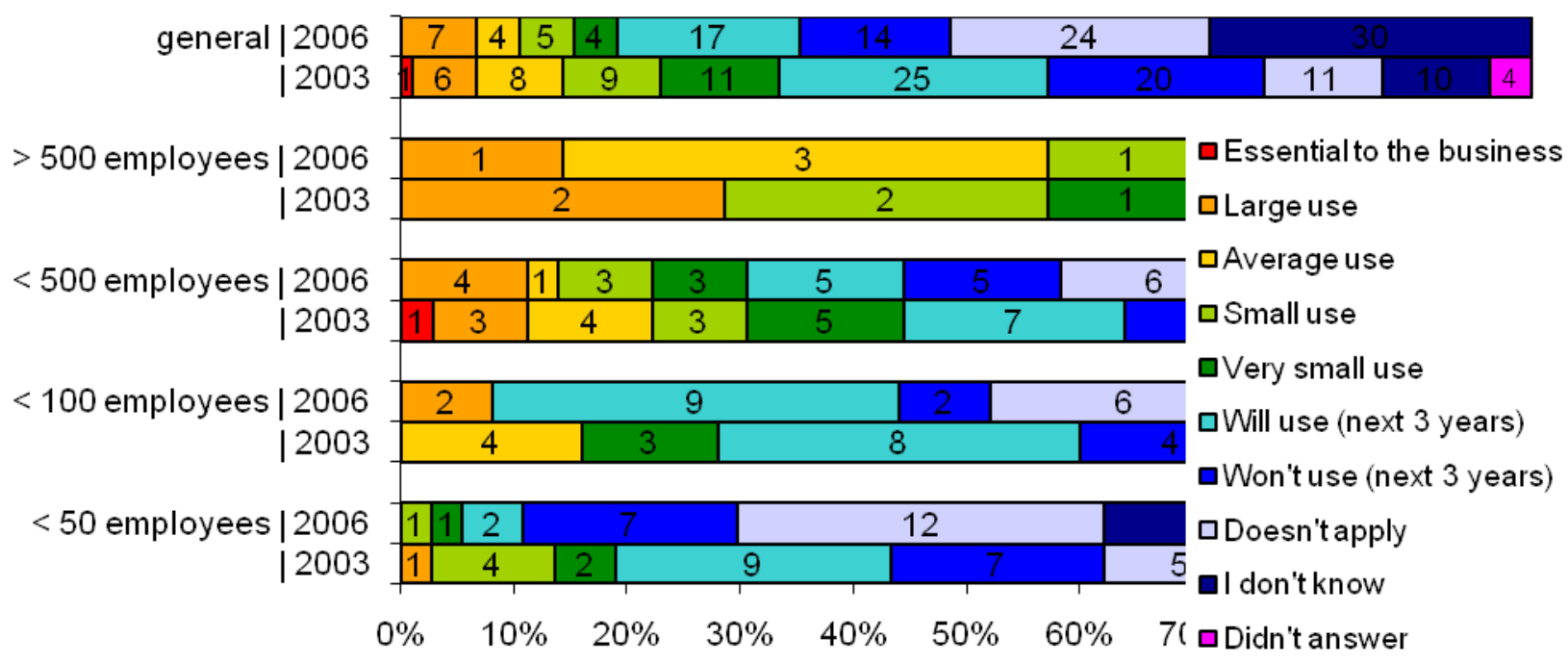

Current use of EDI, segmented according to company size and survey year

\section{Use of extranets}

Extranets are efficient ways of spreading information to business partners. In spite of that, its usage to coordinate activities with suppliers is low, as can be seen in Figure 5. Companies of all sizes could use the Internet more intensively for that, considering the great potential benefits to integration of the supply chain. Companies use extranets to coordinate with customers at a slightly higher level, as shown in Figure 6. This could reflect more concern with the selling side of the company's operation than with the buying one, which could mean that companies have not yet realized the possibilities of the Internet to improve corporate procurement.

\section{Figure 5}

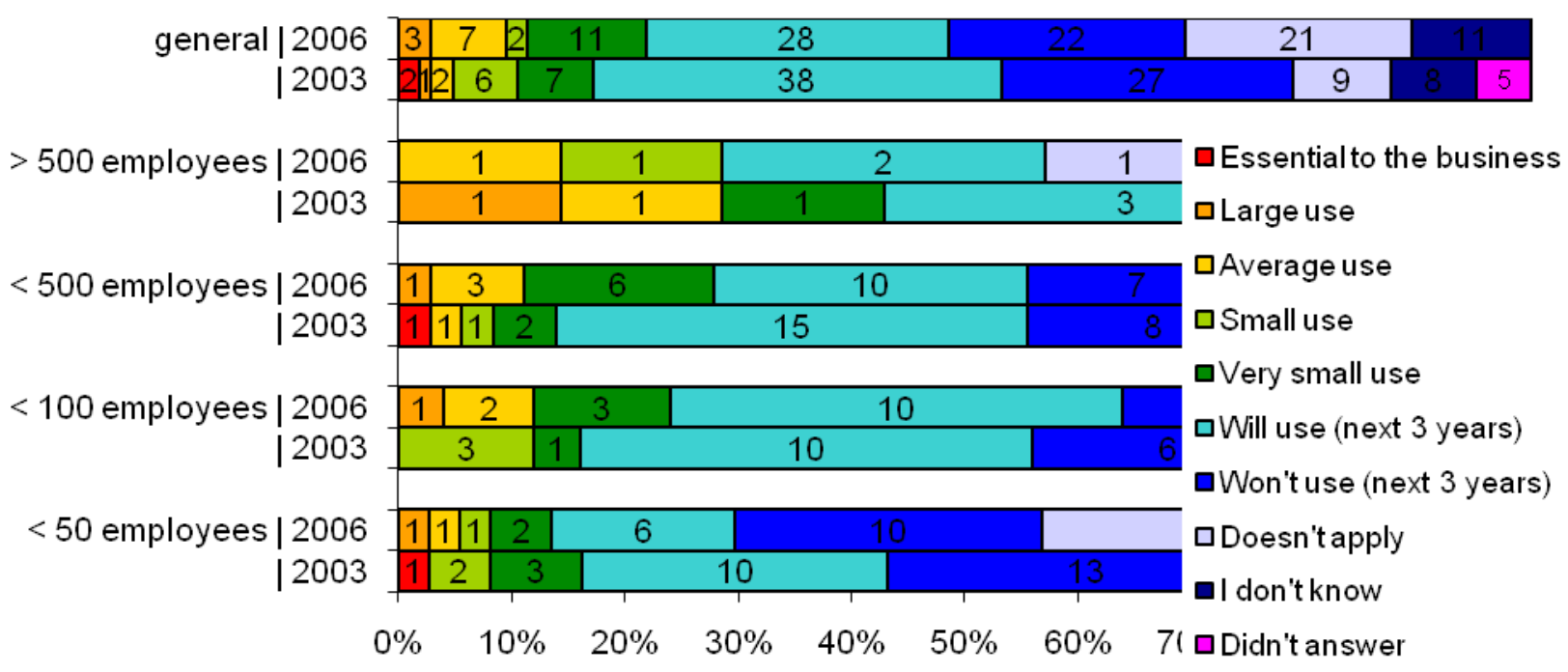

Current use of extranets for suppliers, segmented according to company size and survey year 
Figure 6

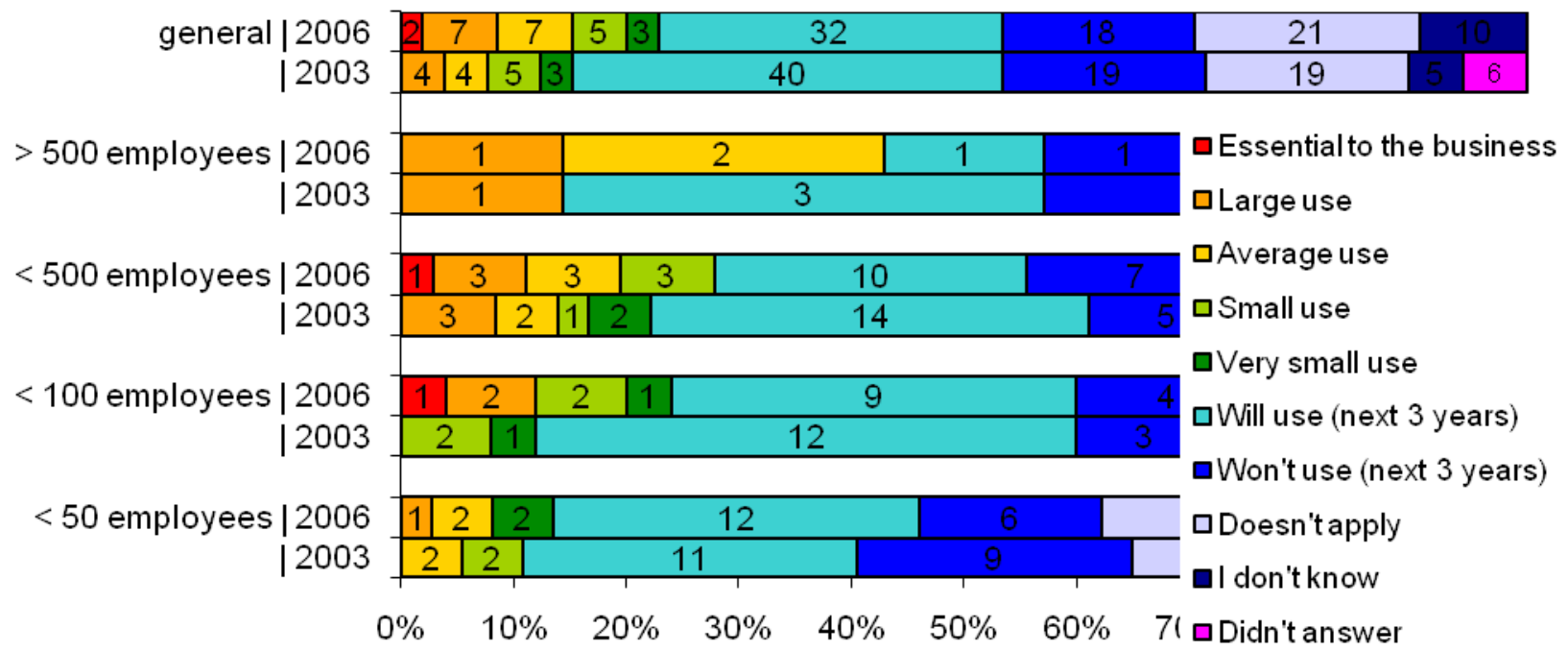

Current use of extranets for customers, segmented according to company size and survey year

\section{CONCLUSIONS}

The participants in the survey were asked about changes in the level of integration of the supply chain and the extent to which the Internet and other IT were responsible for that. They were also questioned about the existence of information systems on their suppliers, and the suppliers of their suppliers (upstream in the supply chain) and about their customers and the customers of their customers (downstream in the supply chain). Then, information was gathered on the technologies used to achieve such information integration along the supply chain.

The results were, in general, compatible with the authors' expectations based on their review of the literature and their own experience. However, one thing that caught the authors' attention was the huge number of industrial companies that do not use or intend to use information systems and the Internet to obtain better knowledge and control over their supply chains (only $5.7 \%$ of the participants claimed that they use information systems that include data on the suppliers of their suppliers at least to a moderate extent and $4.8 \%$ about the customers of their customers). It makes one wonder whether companies give the same importance to the supply chain management issue as academia. Further research might be necessary to prove this point as well as its relevance to the global supply chain management efficiency (Sheu, 2008).

The electronic integration of companies to their customers and suppliers allows customers, at least in theory, to interact directly with their suppliers' pro- duction systems, triggering the production of items they need and leveraging their efficiency. Customers are also able to interrupt the production of items for which their own customers have cancelled orders or change their suppliers' production schedules, in order to increase the priority of items that are more urgently needed.

In addition, being aware of the customers' inventory turnovers and levels of stock at any time, suppliers may be allowed to decide on the delivery of a new batch of products without the requirement of an express order from the customer thereby assuring replenishment in due time.

Such a level of interference in the company's internal processes will only be accepted, however, by companies that trust their partners and have strong common interests (Belso-Martínez, 2006), which can justify giving up part of the their own autonomy to improve the efficiency of the supply chain as a whole.

Even if the technological challenge of connecting different agents in virtual value-adding networks is overcome, other conditions need to be met, in order to ensure the success of such supra-organizational coalitions. If, on the one hand, the dynamics of the environment justifies and stimulates partnerships being settled with companies that perform complementary activities, reducing the risk and increasing the agility of the supply chain, on the other, power balance and interests change over time, thereby challenging the attempt to build long-lasting trust based partnerships. 
Graeml, A. R. Balbinot, Z. Csillag, J. M.: Internet's Role in the Integration of Supply Chains of Manufacturing Organizations in Brazil

\section{REFERENCES}

ALBERTIN, A. L. (2003) Pesquisa FGV - Comércio eletrônico no mercado brasileiro [Electronic commerce in the Brazilian market]. São Paulo: Centro de Informática Aplicada / Programa de Excelência de Negócios na Era Digital - FGV-SP.

BEDNARZ, A. (2004) Internet EDI: Blending old and new. Network World, v.21, n. 8, p. 29-30, Feb 23.

BELSO-MARTÍNEZ, J. (2006) Why are some Spanish manufacturing firms internationalizing rapidly? The role of business and institutional international networks. Entrepreneurship \& Regional Development, v. 18, n. 3, p. 207-226.

COTTRILL, K. (2003) Cutting edge. Traffic World, p. 1, Jul 21.

COYLE, J. J.; BARDI, E. J.; NOVACK, R. A. (1999) Transportation: South-western. Thomson Learning.

FERDOWS, Kasra (2006) Transfer of changing production knowhow. Production \& Operations Management, v. 15, n. 1, p. 1-9.

GEOFFRION, A. M.; KRISHNAN, R. (2001) Prospects for operations research in the e-business era. Interfaces, Mar-Apr.

HANNON, D. (2004) Inbound supply managers ask 3PL providers: got technology? Purchasing, v.133, n. 7, p. 55-58, April 15.

MARQUES, E. V.; DI SERIO, L. C. (2000) O ECR no varejo Brasileiro [ECR in Brazilian retail]. In: Simpósio de Administração da Produção, Logística e Operações Industriais, 3o., São Paulo. Proceedings. POI-FGV. p. 1 CD-ROM.

O'BRIEN, J. A. (2001) Sistemas de informação e as decisões gerenciais na era da internet [Information systems and managerial decisions in the Internet era]. São Paulo: Saraiva.
O'DONNELL, T. et al. (2006) Minimizing the bullwhip effect in a supply chain using genetic algorithms. International Journal of Production Research, v. 44, n. 8, p. 1523-1543.

REID, R. D.; SANDERS, N. R. (2004) Operations Management. New York: John Wiley \& Sons.

SAAB, J.; CORRÊA, H. L. (2004) The Forrester effect reduction: one size fits all? In: Second World Conference on POM and 15th Annual POM Conference, Cancun, Mexico. Proceedings. POMS. p. 1 CD-ROM.

SCHAFFER, B. (1998) Cross docking can increase efficiency. Automatic I.D. News, v.14, n. 8, p. 34-36, Jul.

SHAPIRO, C.; VARIAN, H. R. (1998) Information rules: a strategic guide to the network economy. Boston: Harvard Business School Press. 352 p.

SHEU, Jiuh-Biing (2008) A hybrid neuron-fuzzy analytical approach to mode choice of global logistics management. European Journal of Operational Research, v. 189, n. 3, p. 971-986, Sep.

SLACK, N., et al. (1999) Administração da produção [Operations Management]. São Paulo: Atlas.

SLIWA, C. (2004) EDI: alive and well after all these years. Computerworld, v. 38, n. 24, p. 1, June 14.

STARR, M. K. (2003) Application of POM to e-business: B2C eshopping. International Journal of Operations \& Production Management, v.23, n. 1, p. 105-124.

SWEET, L. L. (1999) Giving them the business. InfoWorld, v. 21, n. 30, p. E2-E4, Jul 26.

THE ECONOMIST. (2000) E-commerce: too few pennies from heaven. The Economist, p. 67, 1-7 July. 


\section{AUTHOR'S BIOGRAPHY}

Alexandre Reis Graeml holds a Doctor and a Masters degree in Business Administration (Operations Management and Information Systems Management) from Fundacao Getulio Vargas (FGV-EAESP), in Sao Paulo. His B.Sc. degree is in Electrical Engineering from the Federal University of Technology - Parana (UTFPR). He is currently an associate professor at the Graduate School of Business of Universidade Positivo and at the IS Department of the Federal University of Technology - Parana (UTFPR). He is a Fulbright fellow and his international academic experience includes having been a visiting scholar at the University of California, in Berkeley, and an invited professor at Ecole Supérieure d'Ingénieurs, in Rouen, France, and at Universidad Europea de Madrid, in Spain. His research interests involve the Internet's impact on organizations and our society, supply chain management and internationalization.

Zandra Balbinot holds a Doctor degree in International Management from the Ecole des Hautes Etudes Commerciales, in Montreal, Canada. She also holds a Masters degree and a Bachelor degree in Business Administration from the Federal University of Rio Grande do Sul (UFRGS). She is currently a professor at the Federal University of Parana (UFPR). Her international experience involves, among other activities, consulting for a Brazil-Canada project for the construction of low-income family houses. Prior to becoming a university professor she was the director of a Canadian software company for South America. Her main research interests concern international business and joint ventures.

João Mário Csillag holds a Doctor and a Masters degree in Business Administration (Operations Management) from Fundacao Getulio Vargas (FGV-EAESP), in Sao Paulo. His B.Sc. degree is in Aeronautical Engineering from the Aeronautical Technology Institute. He is currently a full professor at Fundacao Getulio Vargas - SP, international relations vice-president of the Brazilian Association of Value Engineering, member of the consulting council of the Sao Paulo Management Excellence Institute and a member of the directing council of Mauá Institute of Technology. His main research interests are in Operations Strategy, specially total quality, value analysis, competitiveness, continuous improvement and lead time. 